Review

\title{
The Influence of Bedding Application in Feedlot Cattle: A Review
}

\author{
Dathan Thomas Smerchek and Zachary Kidd Foster Smith \\ Department of Animal Science, South Dakota State University, Brookings, SD 57007, USA
}

\author{
Article history \\ Received: 07-12-2020 \\ Revised: 11-02-2021 \\ Accepted: 23-02-2021 \\ Corresponding Author: \\ Zachary Kidd Foster Smith \\ Department of Animal Science, \\ South Dakota State University, \\ Brookings, SD 5700 \\ Email: zachary.smith@sdstate.edu
}

\begin{abstract}
A sizable portion of cattle on feed in the United States are fed in the Upper Midwest and Northern Plains region where temperatures routinely fall below freezing during late fall, winter and early spring. The persistent cold temperatures coupled with snow accumulation, wind, moisture and ice can cause undesirable pen conditions for confined cattle, ultimately resulting in decreased insulative capacity of cattle hair coat as a result of dampness and mud or manure accumulation. For cattle, the insulative capacity of the haircoat is an important factor related to their lower critical temperature (LTc) threshold. The LTc for homeotherms is the temperature below which the organism's metabolic rate must increase in order to maintain homeostasis. Using bedding to improve cattle comfort and growth performance is a common practice used in livestock production. However, the exact degree to which bedding improves growth performance is difficult to quantify. Some previous work related to the effects of bedding application and differing housing techniques on beef cattle growth performance, carcass characteristics and calculated maintenance coefficient have been done, however, findings have been variable. Thus, during winter months, understanding the amelioration in maintenance requirement as a result of bedding application is crucial as it may allow for more accurate tracking and growth performance prediction in beef cattle. This review of the literature is intended to provide insight into the energetic principles related to increases in energy required for maintenance as a result of a cold environment as well as the influence of bedding application on energy required for maintenance and growth performance in beef cattle fed in cold environments.
\end{abstract}

Keywords: Bedding, Cold Stress, Energetics, Maintenance Requirement, Lower Critical Temperature

\section{Introduction}

\section{Brief History of Nutritional Energetics}

Nutritional energetics relating to animals and man can be traced Nutritional energetics relating to animals and man can be traced back to Lavosier during the 1700 's, who determined that life is essentially a complex combustion reaction and also established the early relationships between $\mathrm{O}_{2}$ and $\mathrm{CO}_{2}$ in the combustion process (Kleiber, 1961). Researchers such as Henry Armsby at Pennsylvania State University, Wilbur Atwater who was the director of the first United States Agricultural Experiment Station at Wesleyan University, Oskar Kellner of the German Agricultural Experiment Station, Max Rubner at the University of Marburg and the University of Berlin, Samuel Brody at the University of Missouri,
Max Kleiber at the University of California - Davis, William Garrett and Glen Lofgreen also at the University of California - Davis and Sir Kenneth Blaxter of Great Britain continued to provide novel insights and concepts that laid the foundation for modern nutritional energetics. This foundation of energetics research would eventually evolve into the modern net energy system that is still used in beef cattle production today.

The laws of thermodynamics, discovered in the 1840 's, are the foundation on which the structure of nutritional energetics reside. The first law of thermodynamics is known as the law of conservation of energy. This law states that energy can neither be created nor destroyed. This law is of vital importance when making calculations related to animal nutrition. This law undergirds the assumption that $\mathrm{ME}=\mathrm{RE}+\mathrm{HE}$, where 
$\mathrm{ME}=$ metabolizable energy, this is energy available to the animal not excreted in gas, urine, or feces; RE = retained energy, energy retained in animal tissue or product; HE = heat energy, heat energy released by the animal (NASEM, 2016). Heat energy can be divided into basal metabolism, heat of activity, formation of products and waste, digestion and absorption and body temperature regulation (Ferrell and Oltjen, 2008). The complexity pertaining to partitioning these subcategories of heat production into meaningful metabolic processes provides great difficulty. The second law of thermodynamics, better known as the law of Hess, states that the total amount of heat released or produced is independent of the path by which this chemical change is brought about. For example, the law of Hess holds that the amount of heat generated from $1-\mathrm{g}$ of carbohydrate being oxidized completely in an adiabatic bomb calorimeter, is the same as the total heat generated from $1-\mathrm{g}$ of carbohydrate being oxidized completely after being consumed by an animal. The final law of thermodynamics holds that a system's entropy approaches a constant value as the temperature approaches absolute zero $(0 \mathrm{~K})$. The law of conservation of energy and the law of Hess are fundamental for nearly all calculations related to animal energetics. Direct calorimetry, through the principles of the laws of thermodynamics, allowed for researchers such as Atwater, Armsby, Blaxter and others to directly measure heat produced by the animal (Ferrell and Oltjen, 2008). Other researchers such as Armsby, Atwater, Kellner and Rubner used open and closed-circuit calorimeters to measure heat or gas production. Perhaps the largest development made in calorimetry occurred upon the development of the Brouwer equation in 1965 (Brouwer, 1965) which allowed researchers to calculate heat production from $\mathrm{O}_{2}$ consumption, $\mathrm{CO}_{2}$ and $\mathrm{CH} 4$ production and urinary $\mathrm{N}$.

Researchers developed energy systems by investigating the effect of different feeds on energy expenditure to better quantify energy values of feedstuffs. Among these early systems were Kellner's starch equivalent system (Kellner and Goodwin, 1909), Atwater's physiological fuel values (PFV) system (Atwater, 1900) and Armsby-Forbes net energy system. Ultimately building upon the body of calorimetry and net energy work conducted in the past, as well as the principles of the laws of thermodynamics, the California Net Energy System (CNES) was developed by Lofgreen and Garrett (1968). The CNES is currently the basis for systems included in the modern revisions of the NRC (1984; 1996; 2016). The CNES was the first system based on RE in the carcass. Lofgreen and Garrett (1968) measured RE in the carcass using the comparative slaughter method and HP was estimated by deducting energy retained from ME intake.
The CNES was the first energy system that quantified the partial efficiency of $\mathrm{ME}$ use for maintenance functions $(\mathrm{km})$ and the partial efficiency of ME use for gain or productive functions $(\mathrm{kg})$. The relationship for these partial efficiencies allows net energy for maintenance $(\mathrm{NEm})$ and net energy for gain $(\mathrm{NEg})$ to be quantified; $\mathrm{NEm}=\mathrm{km} \times \mathrm{ME}, \mathrm{NEg}=\mathrm{kg} \times \mathrm{ME}$ (Ferrell and Oltjen, 2008). The CNES was the first system to assign two net energy values to each feedstuff and in doing so overcame limitations of previously mentioned earlier systems such as Kellner's starch equivalent system (Kellner and Goodwin, 1909), Atwater's physiological fuel values (PFV) system (Atwater, 1900) and Armsby-Forbes net energy system. Kellner's starch equivalent system that was based on the $\mathrm{NE}$ values of feeds for fattening, was the most widely used example of an early system based on NE concepts. The principle limitation being that the CNES overcame was the differing relative efficiencies of feedstuffs when used for maintenance or for gain. In previous systems, forage was undervalued relative to corn or starch when used for maintenance purposes. Suleiman and Mathison (1979), demonstrated that steers appeared to use the digestible energy from wheat straw with efficiencies comparable to that from all-concentrate diets when energy intakes were slightly greater than maintenance.

\section{Cold Environment Effect on Cattle and Maintenance Energy Requirements}

Cold stress resulting from low temperatures (temperatures below the LTc for that animal) activates a number of acute physiological responses in cattle and other species of mammal that then manifest into behavioral changes. Majority of heat loss to a cold environment occurs through the skin. To mitigate this heat loss, a common response to acute cold by all mammals is vasoconstriction of peripheral blood vessels helps decrease loss of energy to the environment and helps conserve heat in vital organs thus maintaining homeostasis. In addition to that, an acute neuroendocrine response will occur via the sympathetic nervous system, that in a general way stimulates the secretion of adrenaline, noradrenaline, $\beta$-endorphin and cortisol (Lenis Sanin et al., 2016). From a physiological standpoint, the primary effect of cortisol that is secreted as a result of cold stress is the mobilization of energy from internal stores for the maintenance of muscular and nervous function and to cause an increase in available energy substrates and general metabolic intensity (Young, 1975; Lenis Sanin et al., 2016). Further evidence of this was reported by Kang et al. (2019) when they evaluated blood parameters during the "cold season" in Korean steers and found that serum glucose concentrations were higher during colder weather which, as suggested by Young (1975), is indicative of increased 
metabolism as a result of a cold environment. Although it has not been extensively studied, Xu et al. (2017) evaluated differential gene expression in Chinese Sahne cattle exposed to severe cold stress. Gene analysis showed that these differentially expressed genes were primarily associated with important biological pathways related to lipid metabolism and cell death and survival. Genes associated with these pathways are likely differentially expressed as an adaptation strategy to cold stress and are likely linked with severe cold stress resistance. Shivering is another form of physiologic response to acute cold stress. Shivering is an involuntary form of muscular work that is controlled by the sympathetic nervous system and the somatic motor system (Nakamura and Morrison, 2011). Shivering involves twitching or contraction of skeletal muscle and can produce endogenous heat through metabolic work in order to compensate for heat loss to the environment and help maintain homeostasis (Young, 1981; DeLee et al., 2010).

In addition to numerous physiological effects resulting from a cold environment, behavioral changes are also noted. Tuomisto et al. (2009) evaluated the effect of different housing systems on growing dairy bulls in Northern Finland. All housing types in this study included a dry bedded area for cattle. Cattle behavior was observed directly using instantaneous sampling with a five-minute sampling interval. It was found that, regardless of housing type, bulls spent more time laying down in winter months than in summer months. In addition to this, bulls used in this study showed strong, almost exclusive, preference for lying on bedded areas that were offered within each housing scenario. The authors interpreted this observation to indicate that provision of a bedded lying area and shelter during sub-optimal weather during winter months is likely to have a positive effect on the welfare of outdoor housed bulls. This author suspects that in addition to an undoubted improvement in animal welfare, this is an instinctive behavioral adaptation rooted in self-preservation during winter months to decrease maintenance energy costs and conserve body heat. This supports findings from other bedding research that will be discussed further in the later portions of this review.

Maintenance can be defined as the state in which there is no net gain nor loss of energy from the body. Within this, the maintenance energy requirement of the animal can be further defined to the amount of energy necessary to achieve and maintain an equilibrium state (Young, 1983). This would include the cost of any minimal muscular activities necessary to consume and process the required number of calories. Lofgreen and Garrett (1968), determined the maintenance energy requirement of beef animals to be $0.077 \mathrm{~W}^{0.75}$ where $\mathrm{NE}_{\mathrm{m}}$ is in Mcal per day and $\mathrm{W}=$ bodyweight in $\mathrm{kg}$. However, the CNES was developed in a thermoneutral environment and so the system itself was not initially created to be dynamic in terms of adaptation to adverse environmental conditions and other potential factors affecting input variables. Although cattle were not actually fed at zero feed intake, to determine the $\mathrm{NE}_{\mathrm{m}}$ requirements for growing and finishing beef cattle, Lofgreen and Garrett (1968), assumed that at zero feed intake, heat increment, which is associated with digestion of feedstuffs and absorption of resulting substrate, is equal to zero and thus the remaining components of heat production are simply basal metabolism and heat associated with activity which can then be considered to be equal to the $\mathrm{NE}_{\mathrm{m}}$.

Basal metabolism or basal metabolic rate (BMR) can be defined as the minimal rate of heat production from the fasted and rested animal when the environmental ambient temperature is within the range of Upper critical Temperature (UTc) and LTc (Kleiber, 1961; Blaxter, 1989). The LTc can vary based on a number of factors related to insulative capacity of hair coat and intake level. The LTc for cattle with $8 \mathrm{~mm}$ hair and ad libitum feed intake is $-1^{\circ} \mathrm{C}$, while a cow with the same hair coat in a fasted state has an LTc of $18^{\circ} \mathrm{C}$ (NRC, 1981). Basal metabolic rate, when determined in man, is measured when the subject is in a post-absorptive state ( 12-hr fast), laying down in complete muscular relaxation and in a thermoneutral environment. Animals provide difficulty when attempting to accurately determine BMR as they cannot be made to stay completely still in a fasted state for measurement. As such, the fasting metabolic rate, or fasting heat production (FHP), is what is usually measured in animals (Blaxter, 1989). Fasting heat production includes heat from voluntary activity of the animal that would be mostly mitigated by muscular relaxation. Basal metabolic rate and FHP will be treated as interchangeable from herein. Basal metabolic rate can be affected by several factors such as previous plane of nutrition, sex, age, body condition score, genetics, stage of production and environmental conditions. If the ambient temperature is below the LTc for a homeotherm, then the organism's metabolic rate must increase in order to maintain homeothermy (Young, 1983). Prolonged exposure to cold environments can have a marked impact on the energy required for maintenance in beef cattle. This increase in maintenance energy required by the beef animal is a result of increased basal metabolic intensity to manage increasing heat production demands to maintain homeothermy during prolonged exposure to temperatures below the animal's LTc. This is not simply an acute response in basal metabolism but is instead indicative of metabolic adaptation to cold (Young, 1981).

Robinson et al. (1986) conducted a study in which treatment groups of four Hereford $\times$ Red Angus yearling 
steers were adapted to a different environmental temperature for a period of 4 months and then heat production and other measures were assessed for a 2 month period. The three temperature treatments that cattle were acclimated to included cold $\left(3^{\circ} \mathrm{C}\right)$, thermoneutrality $\left(20^{\circ} \mathrm{C}\right)$ and heat $\left(35^{\circ} \mathrm{C}\right)$. Robinson et al. (1986) concluded that heat production for cattle adapted to the colder temperature $\left(3^{\circ} \mathrm{C}\right)$ was greater than the heat production of cattle adapted in the thermoneutral temperature. In a similar study, Boyles et al. (1991), housed crossbred steers with an initial weight of $257 \mathrm{~kg}$ in environmental chambers that were acclimated to three temperature treatments $\left(0^{\circ} \mathrm{C}, 5^{\circ} \mathrm{C}\right.$ and $\left.15^{\circ} \mathrm{C}\right)$ for a 7 day period and then a subsequent 28 day experimental period followed. Heat production for cattle exposed to $0^{\circ} \mathrm{C}$ and $5^{\circ} \mathrm{C}$ treatments had increases in heat production of 15 and $23 \%$, respectively, compared to $15^{\circ} \mathrm{C}$ treatment. It is of interest that a linear increase in heat production did not occur as temperature decreased. Instead, a tendency was noted for cattle exposed to $5^{\circ} \mathrm{C}$ to have greater heat production when compared to the $0^{\circ} \mathrm{C}$ treatment. In this study, two of the treatment groups were exposed to the $5^{\circ} \mathrm{C}$ treatment and were then rotated to the $0^{\circ} \mathrm{C}$. The reduced heat production for the $0^{\circ} \mathrm{C}$ group indicates that acclimation occurred when exposed to $5^{\circ} \mathrm{C}$. Researchers Delfino and Mathison (1991) conducted a an experiment where Hereford and Hereford-cross yearling steers with initial body weight (BW) of $340 \mathrm{~kg}$ were fed all concentrate diets in either an indoor temperature controlled environment with no bedding, or outdoors with wood shavings for bedding from January to April. The mean temperatures for indoor and outdoor locations were $16.9 \pm 2.7^{\circ} \mathrm{C}$ and $-7.6 \pm 6.8^{\circ} \mathrm{C}$. It was reported that steers housed outdoors retained $65 \%$ less energy and had an $18 \%$ increase in FHP. Housing steers outdoors resulted in a $41 \%$ increase in ME use for maintenance compared to steers housed indoors.

Following severe winter storms in Colorado, Wagner et al. (2008) conducted a post-hoc analysis that investigated the effect of severe winter weather on net energy for maintenance required by yearling steers. The average temperature experienced by steers included in the post-hoc analysis ranging from December 26, 2006, through February 22, 2007, was $-8.43^{\circ} \mathrm{C}$. Average temperature was calculated from the average of the daily high and daily low temperatures during the period. Data indicated that $\mathrm{NE}_{\mathrm{m}}$ required by cattle during and in the aftermath of a major winter weather event may be 2.5 times higher than $\mathrm{NE}_{\mathrm{m}}$ required under standard thermoneutral feeding conditions. Smerchek and Smith (2020), conducted a pair of studies that evaluated the effects of wheat straw bedding application on the estimated Maintenance coefficient (MQ) of confined beef steer growth performance, carcass characteristics and circulating metabolite response. In experiment 1 ,
Simmental $\times$ Angus crossbred beef steers $(n=240$; initial $\mathrm{BW}=365 \pm 22.5 \mathrm{~kg}$ ) were assigned to treatments of either No bedding (NO) or Bedding (BED). Bedding was applied to BED treatment at a rate of $1.8 \mathrm{~kg}$ of wheat straw bedding/head $\cdot \mathrm{d}^{-1}$. The average ambient temperature and wind chill were $-14.7^{\circ} \mathrm{C}$ and $-17.7^{\circ} \mathrm{C}$, respectively, during the initial $36 \mathrm{~d}$ period of experiment 1. It was during this time that the magnitude of difference in MQ was largest between treatment groups. During the initial $36 \mathrm{~d}$ period of Exp. 1, relative to the BED treatment, NO had an MQ that was elevated $40.4 \%$. Thus, cattle in non-bedded pens required $40.4 \%$ more energy for maintenance compared to steers from BED. The severe environmental conditions during the initial 36-d period, experienced by all cattle on test, caused an increase in the maintenance energy requirements of $89.6 \%$ and $35.1 \%$, respectively, for NO and BED relative to the standard $\mathrm{NE}_{\mathrm{m}}$ requirement value for beef cattle in a thermoneutral environment of $0.077 \mathrm{Mcal} / \mathrm{BW}^{0.75}$ (Lofgreen and Garrett, 1968). Cumulatively, in experiment 1, a $12.4 \%$ increase in MQ was noted for NO compared to BED. Additionally, the cumulative MQ of $\mathrm{NO}$ and BED treatments were increased of $41.5 \%$ and $27.3 \%$, respectively, compared again to the standard $\mathrm{NE}_{\mathrm{m}}$ requirement value for beef cattle in a thermoneutral environment of $0.077 \mathrm{Mcal} / \mathrm{BW}^{0.75}$ (Lofgreen and Garrett, 1968). In a second experiment, Smerchek and Smith (2020), conducted a 56-d receiving study, used 162 newly weaned Charolais x Red Angus crossbred beef steers to evaluate the effects of bedding application $\left(1.8 \mathrm{~kg}\right.$ of wheat straw bedding/head $\left.\cdot \mathrm{d}^{-1}\right)$ on growth performance and maintenance energy requirements during the feedlot receiving phase in newly weaned beef steers. It was reported that non-bedded cattle had an $18.2 \%$ increase in MQ compared to cattle from the bedded treatment during the 56-d receiving study. Increased maintenance energy requirement in order to maintain homeothermy as a response to winter weather conditions such as sustained cold temperatures, snow accumulation and wind are well known beef cattle (Young, 1981; 1983). This principle has been demonstrated in a number of previous studies dealing with bedding application and cold stress (Birkelo and Lounsberry, 1992; Stanton et al., 1994; Anderson et al., 2006; Mader and Colgan, 2007; Smerchek and Smith, 2020). Table 1 summarizes previous bedding studies and the subsequent effect bedding application had on calculated Maintenance coefficient (MQ). The MQ was calculated based upon observed growth performance, dry matter intake, tabular diet NE values and metabolic body weight. Retained energy (RE, Mcal/d) from observed ADG was determined using: $\mathrm{RE}=0.0557 \mathrm{~W}^{0.75} \times$ ADG1.097 where $\mathrm{W}$ is the mean equivalent shrunk BW (mean feeding BW $\times(478 /$ body weight at estimated $28 \%$ empty body fatness) according to NRC (1996). 


\begin{tabular}{|c|c|c|c|c|c|c|c|}
\hline Source & Period (days) & Animal description & $\begin{array}{l}\text { Period start } \\
\mathrm{BW}, \mathrm{kg}\end{array}$ & $\begin{array}{l}\text { Treatment } \\
\text { description }\end{array}$ & $\begin{array}{l}\text { MQ, Mcal/ } \\
\mathrm{BW}^{0.75 \text { a }}\end{array}$ & $\begin{array}{l}\text { Change from } \\
0.077, \text { Mcal/ } \\
\mathrm{BW}^{0.75}, \%\end{array}$ & $\begin{array}{l}\text { Increase relative } \\
\text { to beddin } \\
\mathrm{g} \text { (treatment), \% }\end{array}$ \\
\hline \multirow[t]{3}{*}{$\begin{array}{l}\text { Anderson et al. } \\
\text { (2006) }\end{array}$} & Cumulative (n/a) & Preconditioned Steer Calves & 329 & No bedding & 0.117 & 52.37 & $\begin{array}{l}96.1 \text { (moderate) and } \\
57.0 \text { (generous) }\end{array}$ \\
\hline & Cumulative (n/a) & Preconditioned Steer Calves & 329 & Moderate Bedding & 0.060 & -22.29 & - \\
\hline & Cumulative (n/a) & Preconditioned Steer Calves & 329 & $\begin{array}{l}\text { Generous Bedding }(2 \times \\
\text { moderate bedding) }\end{array}$ & 0.075 & -3.11 & - \\
\hline \multirow[t]{6}{*}{$\begin{array}{l}\text { Birkelo and } \\
\text { Lounsberry (1992) }\end{array}$} & Growing (1-82) & Crossbred steers & 265 & No bedding & 0.072 & -6.0 & $\begin{array}{l}9.0 \text { (oat straw) and } 0.0 \\
\text { (newspaper) }\end{array}$ \\
\hline & Growing (1-82) & Crossbred steers & 265 & Bedding (oat straw) & 0.066 & -13.7 & - \\
\hline & Growing (1-82) & Crossbred steers & 264 & Bedding (newspaper) & 0.072 & -6.0 & - \\
\hline & Finishing (83-189) & Crossbred steers & 370 & No bedding & 0.111 & 43.9 & $\begin{array}{l}12.4 \text { (oat straw) and } \\
17.0 \text { (newspaper) }\end{array}$ \\
\hline & Finishing (83-189) & Crossbred steers & 375 & Bedding (oat straw) & 0.099 & 28.1 & - \\
\hline & Finishing (83-189) & Crossbred steers & 372 & Bedding (newspaper) & 0.094 & 22.5 & - \\
\hline \multirow{2}{*}{$\begin{array}{l}\text { Mader and Colgan } \\
\text { (2007). Trial } 1\end{array}$} & Cumulative (d 1-110) & Crossbred Steers & 374 & No Bedding & 0.084 & 9.2 & 3.1 \\
\hline & Cumulative (d 1-110) & Crossbred Steers & 374 & $\begin{array}{l}\text { Bedding }(1.0 \mathrm{~kg} \text { of wheat } \\
\left.\text { straw bedding } / \mathrm{head}^{-1} \mathrm{~d}^{-1}\right)\end{array}$ & 0.082 & 5.9 & - \\
\hline \multirow{3}{*}{$\begin{array}{l}\text { Mader and Colgan } \\
\text { (2007). Trial } 2\end{array}$} & Interim (d 1-34) & Crossbred Steers & 400 & No Bedding & 0.105 & 36.8 & 8.6 \\
\hline & Cumulative (d 1-124) & Crossbred Steers & 400 & No Bedding & 0.086 & 11.9 & 6.7 \\
\hline & Cumulative (d 1-124) & Crossbred Steers & 400 & $\begin{array}{l}\text { Bedding }(1.0 \mathrm{~kg} \text { of wheat } \\
\left.\text { straw bedding } / \text { head } \cdot \mathrm{d}^{-1}\right)\end{array}$ & 0.081 & 4.8 & \\
\hline \multirow{4}{*}{$\begin{array}{l}\text { Smerchek and Smith } \\
(2020) \text {. Experiment } 1^{\text {b }}\end{array}$} & Receiving (d 1-36) & Simmental x Angus Steers & 365 & No bedding & 0.146 & 89.6 & 40.4 \\
\hline & Receiving (d 1-36) & Simmental x Angus Steers & 365 & $\begin{array}{l}\text { Bedding }(1.8 \mathrm{~kg} \text { of wheat } \\
\left.\text { straw bedding } / \mathrm{head}^{-1} \mathrm{~d}^{-1}\right)\end{array}$ & 0.104 & 35.1 & - \\
\hline & Cumulative (d 1-178) & Simmental x Angus Steers & 365 & No bedding & 0.109 & 41.5 & 12.4 \\
\hline & Cumulative (d 1-143) & Simmental x Angus Steers & 365 & $\begin{array}{l}\text { Bedding }(1.8 \mathrm{~kg} \text { of wheat } \\
\left.\text { straw bedding } / \text { head } \cdot \mathrm{d}^{-1}\right)\end{array}$ & 0.098 & 27.3 & - \\
\hline \multirow{2}{*}{$\begin{array}{l}\text { Smerchek and Smith } \\
\text { (2020). Experiment } 2\end{array}$} & Cumulative (d 1-56) & Charolais x Red Angus Steers & 278 & No bedding & 0.052 & -32.5 & 18.2 \\
\hline & Cumulative (d 1-56) & Charolais x Red Angus Steers & 278 & $\begin{array}{l}\text { Bedding }(1.0 \mathrm{~kg} \text { of wheat } \\
\left.\text { straw bedding } / \text { head } \cdot \mathrm{d}^{-1}\right)\end{array}$ & 0.044 & -43.0 & - \\
\hline \multirow{4}{*}{$\begin{array}{l}\text { Stanton et al. } \\
\text { (1994) }\end{array}$} & Interim (d 28-56) & Steers and heifers & 414 & No bedding & 0.094 & 21.5 & 47.0 \\
\hline & Interim (d 28-56) & Steers and heifers & 414 & Bedding & 0.064 & -17.3 & - \\
\hline & Cumulative (d 1-124) & Steers and heifers & 370 & No bedding & 0.058 & -24.4 & 27.2 \\
\hline & Cumulative (d 1-124) & Steers and heifers & 369 & Bedding & 0.046 & -40.6 & - \\
\hline
\end{tabular}

$\mathrm{MQ}=$ Calculated Maintenance Coefficient, $\mathrm{Mcal} / \mathrm{BW}, \mathrm{kg}^{0.7}$

${ }^{\mathrm{b}}$ Cattle were not fed for an equal number of days. Cattle from the non-bedded treatment required an additional $35 \mathrm{~d}$ to achieve a similar compositional endpoint relative to the bedded treatment

Tabular diet net energy for gain $(\mathrm{NEg})$ values were used to estimate the amount of DMI $(\mathrm{kg})$ that was required for the observed ADG and this amount of feed was noted as feed for gain (FFG). Next, FFG was subtracted from total observed DMI, hence, the remaining feed was used exclusively for maintenance (FFM). Total FFM and tabular dietary Net Energy for maintenance (NEm) values were used to determine the Mcal avaliable for maintenance each day. The total Mcal available for maintenance was then divided by metabolic body weight (median feeding $\mathrm{BW}^{0.75}, \mathrm{~kg}$ ) to determine the metabolic rate $\left(\mathrm{Mcal} / \mathrm{BW}^{0.75}, \mathrm{~kg}\right)$.

\section{Effect of Bedding Application on Cattle Performance}

The geographical location of a cattle feeding operation dictates the environmental conditions and challenges that will be encountered. Cattle fed in the southern United States and High Plains region deal with persistent high temperatures and dry, dusty pen conditions. Cattle fed in the upper Midwest experience mild temperatures during late spring and summer months, however during late fall, winter and early spring, persistent cold temperatures coupled with snow accumulation, wind and ice can cause undesirable pen conditions for cattle. Undesirable pen conditions can result in decreased insulative capacity of the cattle hair coat as the result of dampness and mud or manure accumulation. For cattle, the insulative capacity of the haircoat is an important factor related to their LTc threshold (Wagner et al., 2008). Total insulation can be described as a function of tissue insulation (subcutaneous fat and hide), coat insulation (hair coat) and air insulation (Blaxter, 1989). Mud, moisture and wind can compromise the insulative capacity of the hair coat thus allowing for both acute and persistent increases in heat loss. Smerchek and Smith (2019) evaluated hide tag accumulation (mud and manure attached to hair coat and skin) scores in beef steers and heifers during late winter and spring by using a subjective scoring scale that ranged from 1 to $5(1=$ no tag, clean hide and $5=$ substantial lumps of manure attached to the hide continuously on the underbelly and side of the animal from brisket to rear quarter). Treatments that were applied to cattle whose hide tag accumulation was assessed: (1) $2.5 \mathrm{~kg}$ (as is basis) of bedding/animal $\cdot \mathrm{d}^{-1}$ ( $\mathrm{n}=8$ pens; $\mathrm{HI}$ ); (2) $1.8 \mathrm{~kg}$ (as is basis) of bedding/animal $\cdot \mathrm{d}^{-1}(\mathrm{n}=15$ pens; LO); or (3) no bedding ( $\mathrm{n}=15$ pens; NO). Hide tag assessment in late March (winter) and early May (spring) of 2019 indicated that greater amounts of bedding applied per animal results in less severe tag score. Smerchek and Smith (2019) also showed that hide tag score became less severe as the season changed from winter to spring. The potential 
mitigation of hide tag accumulation offered by bedding application is one of the primary ways by which bedding can improve insulative capacity and ultimately reduce maintenance costs of the animal.

A limited amount of work has been done to directly investigate the effects of bedding application on feedlot cattle growth performance and, specifically, the resulting alterations in energetic demand. Results have been variable with regards to feedlot growth performance and carcass characteristics. The observed inconsistency in performance response to bedding application is likely related to several external factors that play a crucial role in the outcome of performance results. These factors include ambient temperature, wind, precipitation, pen size, stocking density, condition of hair coat and age of animal among other things. This is of importance, as modern tracking systems used to predict cattle performance rely on two previously discussed requirements of the beef animal, $\mathrm{NE}_{\mathrm{m}}$ and $\mathrm{NE}_{\mathrm{g}}$ (Lofgreen and Garrett, 1968). Thus, during winter months, understanding the alteration in basal metabolic rate and thus net energy required for maintenance is crucial as it is directly correlated to feed available for gain (FFG) and may allow for more accurate tracking and performance prediction.

Anderson et al. (2006), using preconditioned steer calves with an initial BW of $329 \mathrm{~kg}$, investigated the effects of bedding level on beef steer growth performance and carcass characteristics. Wheat straw bedding level treatments included no bedding, modest bedding and generous bedding, which was simply $2 \times$ the amount of the "modest" bedding treatment. The modest bedding treatment was applied on a subjective judgment basis to keep bedding available for steers to lay on. It was reported that during winter months both modest and generous amounts of bedding applied during the initial phase of the feeding period resulted in an approximately $20 \%$ increase in ADG. Birkelo and Lounsberry (1992) used crossbred beef steers with an initial BW of $265 \mathrm{~kg}$ to evaluate the effect of oat straw and newspaper bedding as well as housing system in a trial ranging from November through May where the average temperature was approximately $1^{\circ} \mathrm{C}$. Bedding was applied every 3 to 10 days to maintain a dry spot large enough for all steers to lay down at one time. The reported improvement in ADG as a result of bedding application regardless of bedding type was $8.3 \%$. Stanton et al. (1994) used both steers and heifers with an initial BW of $370 \mathrm{~kg}$ to evaluate the effects of wheat straw bedding application on cattle growth performance and carcass characteristics. The study began in January, bedding was applied 10 times throughout the study at a rate of $15.4 \mathrm{~kg} / \mathrm{hd}$ and the average temperature during the study was approximately 5.5 C. Stanton et al. (1994) reported a 5.3\% increase in ADG as a result of bedding application. Mader and Colgan (2007) conducted two trials beginning in mid-
December using crossbred beef steers to evaluate the effect of oat straw bedding application, pen stocking density and facility type. In both trials, bedding was applied at a rate of approximately $1 \mathrm{~kg} / \mathrm{steer} \cdot \mathrm{d}^{-1}$. Trials 1 and 2 used crossbred beef steers with initial BW of 373 and $400 \mathrm{~kg}$, respectively and average temperature during both trials was approximately $0^{\circ} \mathrm{C}$. However, in contrast to the previously discussed studies, it was reported that bedding application, in both trials 1 and 2, did not cause a significant response in ADG. Smerchek and Smith (2020), in experiment 1 , found that bedding application resulted in a $21.0 \%$ increase in ADG and that cattle from the non-bedded treatment required an additional 35 days to reach a similar compositional endpoint. In some previous work, during winter and spring months, final BW was increased in bedded treatments compared to non-bedded controls when cattle were marketed at equal days on feed (Birkelo and Lounsberry, 1992; Anderson et al., 2006). This is attributed to the mathematical relationship between dietary intake energy, energy required for maintenance and the resulting proportion of intake energy that is ultimately available to be used for gain or productive function. Bedded steers, due to decreased maintenance energy requirements, likely had a greater proportion of intake energy available for gain, thus when cattle were harvested at equal days, bedded cattle had greater final BW.

Cold temperatures are known to stimulate appetite as a mechanism to cope with the concurrent increase in metabolic demand of the animal (NRC, 1987). Interestingly, most previous work conducted regarding the effects of bedding on feedlot growth performance during winter months did not report any differences in dry matter intake (DMI) as a result of bedding application (Birkelo and Lounsberry, 1992; Stanton et al., 1994; Anderson et al., 2006; Mader and Colgan, 2007). However, Smerchek and Smith (2020) reported 5.8\% in DMI for bedded in experiment one, conversely, a $4.6 \%$ increase in DMI was noted for non-bedded cattle in experiment 2. A common physiological reaction of ruminants, in addition to increased intake when exposed to cold stress, has been shown to be increased reticulorumen motility and rate of passage of digesta (Westra and Christopherson, 1976). Westra and Christopherson (1976), exposed shorn lambs to treatment temperatures of 21.2 and $1.3^{\circ} \mathrm{C}$ for $4-6$ weeks and observed that the mean number of reticulum contractions per hour was increased $21 \%$ for sheep exposed to $1.3^{\circ} \mathrm{C}$. The physiological response of increased digesta flow, along with increased rate of basal metabolism, may account for the observed disparity in feed efficiency observed in some previous publications. Several previous studies have reported improved feed efficiency as a result of bedding application (Birkelo and Lounsberry, 1992; Anderson et al., 2006; Mader and Colgan, 2007; Smerchek and Smith, 2020). Smerchek 
and Smith (2020), during the initial $36 \mathrm{~d}$ period of experiment 1 , when the average ambient temperature was $-14.7^{\circ} \mathrm{C}$ and wind chill was $-17.7^{\circ} \mathrm{C}$, reported a $49.2 \%$ increase in feed efficiency as a result of bedding application, conversely in experiment 2 , when weather conditions were less severe, the feed efficiency improvement for bedded cattle was only 5.6\%. The degree to which bedding application affects feed efficiency may be largely dependent on several environmental factors.

\section{Effects of Bedding Application on Carcass Characteristics}

As cattle are subjected to cold stress, dietary energy is diverted towards maintenance function. Bedding application, shelterbelts, wind fence and sheltered housing facilities have been shown to mitigate negative effects of the environment that are responsible for increases in required energy for maintenance. It can be expected that in addition to bedding application altering live growth performance, it may impact carcass characteristics as well. Anderson et al. (2006), evaluated effects of bedding level on feedlot cattle performance, reported that "generous" bedding level improved hot carcass weight $(\mathrm{HCW})$ in bedded pens for cattle fed for equal days. However, in previous work, other authors (Stanton et al., 1994; Mader and Colgan, 2007) reported no effect on HCW for beef cattle fed for equal days. Smerchek and Smith (2020) observed a tendency for non-bedded steers to have heavier HCW compared to steers from the bedded treatment in experiment 1 . However, it must be noted that in experiment 1 , had cattle been harvested at an equal number of days on feed, it is likely that a response in HCW favoring BED cattle would have been noted given cattle from NO required an additional $35 \mathrm{~d}$ to achieve final live $\mathrm{BW}$ similar to that of the BED treatment. Anderson et al. (2006) reported a 5\% increase in REA for bedded steers compared to nonbedded steers fed for equal days. Limited additional data is available reporting the effect of bedding application on REA in beef steers fed for an equal number of days. Mader and Colgan (2007) reported that bedding did not cause a significant response in dressing percentage in either of their two trials. In previous work where bedded treatments had improved dressing percentages compared to non-bedded cattle (Stanton et al., 1994; Anderson et al., 2006). Anderson et al. (2006) reported no difference in $\mathrm{RF}$ as a result of bedding application. Mader and Colgan (2007) reported no difference in marbling score as a result of bedding application in both bedding trials. In an initial trial, Anderson et al. (2006) reported an improvement in marbling score favoring bedded cattle, however, in the following trial, no effect on marbling score was observed. An improvement in marbling score was reported by Smerchek and Smith (2020) for non-bedded steers compared to bedded steers in experiment 1 . Discrepancies in USDA marbling score in bedded vs. non-bedded cattle could potentially be related to the relationship between $\mathrm{NE}_{\mathrm{m}}$ and $\mathrm{NE}_{\mathrm{g}}$; as maintenance requirements increase, feed available for gain subsequently decreases unless this disparity is compensated for in the form of increased intake. Garrett (1980) stated that the composition of gain appears to an important factor affecting $\mathrm{k}_{\mathrm{g}}$, thus, differences in growth rates resulting from bedding application would likely affect composition of gain and thus marbling deposition.

\section{Economic Impact of Bedding Application}

Input prices relative to cattle feeding, due to the nature of cattle and commodity markets, are in a constant state of flux. However, based upon the value of body weight gain and cost of body weight gain one can may assess the value of bedding application. The following examples will include 3 different types of bedding with varying costs applied at a rate of $4 \mathrm{lbs}$ (as-is basis)/head $\cdot \mathrm{d}^{-1}$ : (1) corn stalks (30.00 \$/ton), (2) wheat straw (70.00 \$/ton) or (3) wheat straw (145.00 \$/ton). Underlying assumptions included in the economic analysis include: (1) initial body weight of $1000 \mathrm{lbs}$, (2) 60 day feeding period, (3) value of body weight gain of $0.80 \$ / \mathrm{lb}$, (4) a $64 \mathrm{Mcal} / 45.4 \mathrm{~kg} \mathrm{NEg}$ diet priced at $180.00 \$ /$ ton (dry matter basis), (5) equal dry matter intake between bedded and non-bedded groups, (6) increases net energy for maintenance requirement of $34 \%$ for bedded cattle and $88 \%$ increase for non-bedded cattle, (7) yardage of $0.35 \$ / \mathrm{head}^{-\mathrm{d}^{-1}}$, (8) estimated loader cost of $72.50 \$$ /hour, (9) estimated labor time of 1 hour/week for a 150 head pen (labor cost of $0.07 \$ /$ head $^{-1} \mathrm{~d}^{-1}$ ) and the bedding cost of $0.06 \$ /$ head $^{-1} \mathrm{~d}^{-1}$ for corn stalks, 0.14 $\$ /$ head $\mathrm{d}^{-1}$ for the less expensive wheat straw and 0.29 $\$ /$ head $\cdot \mathrm{d}^{-1}$ for the expensive wheat straw. The in and out cost for corn stalks is $0.129 \$ / h_{e a d} \cdot \mathrm{d}^{-1}, 0.209 \$ / \mathrm{head} \cdot \mathrm{d}^{-1}$ for the less expensive wheat straw and $0.359 \$ / h^{2} a d \cdot \mathrm{d}^{-1}$ for the more expensive wheat straw. Thus, the return on investment (ROI) for corn stalks was 6.3 to 1 , for less expensive wheat straw ROI was 3.9 to 1 and for the more expensive wheat straw ROI was 2.3 to 1 . Another example can be used where all assumptions remain the same except that assumption 2 is changed to a 120 day feeding period, assumption 5 is changed to reduced intake of $5.5 \%$ for non-bedded and assumption 6 is changed to a $26 \%$ increase in metabolic rate for bedded cattle and a $42 \%$ increase in metabolic rate for nonbedded cattle. The in and out daily cost does not change from above for daily labor or bedding cost. In this second example, ROI is 1.7 to 1 for the corn stalks, 1.3 to 1 for the less expensive wheat straw and 0.9 to 1 for the expensive wheat straw. This second example suggests that even if the wintertime conditions are not severe, much like the alterations in metabolic rate observed by Smerchek and Smith (2020) in their initial experiment (Exp. 1). The ROI for bedding is not very 
great. A key point here is that one will likely incur the cost associated with bedding cattle no matter what they choose to do (i.e. the additional 35 days of yardage and feed costs for the non-bedded steers in experiment 1 from Smerchek and Smith (2020)). Even if the ROI for bedding is not large, the steers from experiment 1 took and extra 35 days to achieve a marketable end body weight compared to the bedded steers.

\section{Conclusion to Review}

Exposure to cold environments below the LTc increases the energy required for maintenance in homeotherms and beef cattle are no exception (Young, 1983). Bedding confined cattle during winter months in regions where snow accumulation, wind, moisture and ice are highly prevalent has been shown to be of value when considering growth performance and carcass characteristics (Birkelo et al., 1991; Stanton et al., 1994; Anderson et al., 2006; Mader and Colgan, 2007; Smerchek and Smith, 2020). Cattle growth performance improvements observed during previous work evaluating the effects of bedding applications are indicative that bedding application alters energy required for maintenance through mechanisms such as reduced conductive heat loss to the pen surface and improved insulative capacity of the hair coat. Thus, during winter months, understanding the maintenance requirement is crucial due to the mathematical relationship maintenance energy has with intake energy and consequently energy available to gain. Better understanding of the effects of bedding application on maintenance requirements will allow for more accurate tracking and growth performance prediction in beef cattle.

\section{Acknowledgment}

This research was sponsored in part by: National Institute of Food and Agriculture, the South Dakota State University Experiment Station (HATCHSD00H690-19) and the Beef Nutrition Program at South Dakota State University.

\section{Author's Contributions}

Dathan Thomas Smerchek: Conceptualization, summarizing of data and writing original draft.

Zachary Kidd Foster Smith: Conceptualization, funding acquisition and editing original draft.

\section{Ethics}

Data used in the analyses reported in this paper were generated from published literature; therefore, no live animals were used by the authors in conducting this project. The authors declare no conflict of interest.

\section{References}

Anderson, V. L., Wiederholt, R. J., \& Schoonmaker, J. P. (2006). Effects of bedding feedlot cattle during the winter on performance, carcass quality and nutrients in manure. 2006 NDSU Carrington Research Extension Center Feedlot Research Rep, 29, 28-36. https://www.ag.ndsu.edu/Carringtonrec/documents/li vestockrd/docs2006/Effects\%20of\%20Bedding.pdf

Atwater, W. O. (1900). Discussion of the terms digestibility, availability and fuel value. 12th Annual report. Storrs. Agricultural Experimental Station. Storrs, Connecticut, 69.

Birkelo, C. P., Johnson, D. E., \& Phetteplace, H. P. (1991). Maintenance requirements of beef cattle as affected by season on different planes of nutrition. Journal of Animal Science, 69(3), 1214-1222. https://doi.org/10.2527/1991.6931214x

Birkelo, C. P., \& Lounsbery, J. (1992). Effect of straw and newspaper bedding on cold season feedlot performance in two housing systems. https://openprairie.sdstate.edu/cgi/viewcontent.cgi?r eferer=https://scholar.google.com/\&httpsredir=1\&ar ticle $=1011 \&$ context=sd_beefreport_1992

Blaxter, K. (1989). Energy metabolism in animals and man. CUP Archive.

Boyles, S. L., Riley, J. G., Lusby, K. S., \& White, T. W. (1991). Metabolic Heat Production of Brahmanx Angus and Hereford $\times$ Angus Steers at 0, 5 and 15 C. The Professional Animal Scientist, 7(4), 33-36. https://doi.org/10.15232/S1080-7446(15)32222-1

Brouwer, E. (1965). Report of sub-committee on constants and factors. In Proceedings of the 3rd symposium on energy metabolism of farm animals, 1965 (Vol. 11, pp. 441-443). European association for animal production. https://ci.nii.ac.jp/naid/10025835799/

DeLee, J., Drez, D., \& Miller, M. D. (2010). DeLee \& Drez's orthopaedic sports medicine: principles and practice. Saunders/Elsevier. ISBN-10: 141603143X.

Delfino, J. G., \& Mathison, G. W. (1991). Effects of cold environment and intake level on the energetic efficiency of feedlot steers. Journal of Animal Science, 69(11), 4577-4587. https://doi.org/10.2527/1991.69114577x

Ferrell, C. L., \& Oltjen, J. W. (2008). ASAS Centennial Paper: Net energy systems for beef cattle-Concepts, application and future models. Journal of Animal Science, $\quad$ 86(10), 2779-2794. https://doi.org/10.2527/jas.20080954

Garrett, W. N. (1980). Factors influencing energetic efficiency of beef production. Journal of Animal Science, 51(6), 1434-1440. https://doi.org/10.2527/jas1981.5161434x 
Kang, H. J., Piao, M. Y., Park, S. J., Na, S. W., Kim, H. J., \& Baik, M. (2019). Effects of ambient temperature and rumen-protected fat supplementation on growth performance, rumen fermentation and blood parameters during cold season in Korean cattle steers. Asian-Australasian Journal of Animal Sciences, 32(5), 657. https://doi.org/10.5713/ajas.18.0621

Kellner, O., \& Goodwin, W. (1909). The Scientific Feeding of Animals... Authorised Translation by William Goodwin. Duckworth \& Company.

Kleiber, M. (1961). The fire of life. An introduction to animal energetics. The fire of life. An introduction to animal energetics. https://www.cabdirect.org/cabdirect/abstract/196214 04881

Lenis Sanin, Y., Zuluaga Cabrera, A. M., \& Tarazona Morales, A. M. (2016). Adaptive responses to thermal stress in mammals. Revista de Medicina Veterinaria, (31), 121-135. https://doi.org/10.19052/mv.3715

Lofgreen, G. P., \& Garrett, W. N. (1968). A system for expressing net energy requirements and feed values for growing and finishing beef cattle. Journal of Animal Science, 27(3), 793-806. https://doi.org/10.2527/jas1968.273793x

Mader, T. L., \& Colgan, S. L. (2007). Pen density and straw bedding during feedlot finishing. Nebraska Beef Cattle Reports. 70. https://digitalcommons.unl.edu/animalscinbcr/70/

Nakamura, K., \& Morrison, S. F. (2011). Central efferent pathways for cold-defensive and febrile shivering. The Journal of Physiology, 589(14), 3641-3658. https://doi.org/10.1113/jphysiol.2011.210047

NASEM. (2016). Nutrient requirements of beef cattle. National Academies of Sciences, Engineering and Medicine.

NRC. (1981). Effect of environment on nutrient requirements of domestic animals.

NRC. (1984). Nutrient requirements of beef cattle. Washington (DC): The National Academies Press.

NRC. (1987). Predicting feed intake of food-producing animals. National Academies Press.

NRC. (1996). Nutrient Requirements of Beef Cattle. Washington (DC): The National Academies Press.

NRC. (2016). Nutrient requirements of beef cattle. Washington DC: National Academies Press.

Robinson, J. B., Ames, D. R., \& Milliken, G. A. (1986). Heat production of cattle acclimated to cold, thermoneutrality and heat when exposed to thermoneutrality and heat stress. Journal of Animal Science, 62(5), 1434-1440. https://doi.org/10.2527/jas1986.6251434x
Smerchek, D., \& Smith, Z. K. (2019). PSIV-B-30 LateBreaking: Effects of wheat straw bedding usage on hide tag scores during winter and spring in finishing feedlot cattle fed in eastern South Dakota. Journal of Animal Science, 97(Suppl 3), 323. https://doi.org/10.1093/jas/skz258.650

Smerchek, D. T., \& Smith, Z. K. (2020). Bedding Application to Feedlot Steers: Influence on Growth Performance, Estimated Maintenance Coefficient, Carcass Characteristics and Circulating Metabolites in Beef Steers. Animals, 10(10), 1766. https://doi.org/10.3390/ani10101766

Stanton, T. L., Schutz, D. N., Anderson, D. C., \& Guthrie, L. D. (1994). Effect of bedding on finishing cattle performance and carcass characteristics. The Professional Animal Scientist, 10(4), 153-155. https://doi.org/10.15232/S1080-7446(15)31971-9

Suleiman, A., \& Mathison, G. W. (1979). Net energy evaluation of barley diets for cattle in cold environments. Journal of Animal Science, 48(6), 1447-1456. https://doi.org/10.2527/jas1979.4861447x

Tuomisto, L., Huuskonen, A., Ahola, L., \& Kauppinen, R. (2009). Different housing systems for growing dairy bulls in Northern Finland-effects on performance, behaviour and immune status. Acta Agriculturae Scand Section A, 59(1), 35-47. https://doi.org/10.1080/09064700902919074

Wagner, J. J., Grubb, P. T., \& Engle, T. E. (2008). Case Study: The effects of severe winter weather on net energy for maintenance required by yearling steers. The Professional Animal Scientist, 24(5), 494-499. https://doi.org/10.15232/S1080-7446(15)30883-4

Westra, R., \& Christopherson, R. J. (1976). Effects of cold on digestibility, retention time of digesta, reticulum motility and thyroid hormones in sheep. Canadian Journal of Animal Science, 56(4), 699-708. https://doi.org/10.4141/cjas76-083

Xu, Q., Wang, Y. C., Liu, R., Brito, L. F., Kang, L., Yu, Y., ... \& Liu, A. (2017). Differential gene expression in the peripheral blood of Chinese Sanhe cattle exposed to severe cold stress. Genetics and Molecular Research, 16(2). https://doi.org/10.4238/gmr16029593

Young, B. A. (1975). Temperature-induced changes in metabolism and body weight of cattle (Bos taurus). Canadian Journal of Physiology and Pharmacology, 53(5), 947-953. https://doi.org/10.1139/y75-129

Young, B. A. (1981). Cold stress as it affects animal production. Journal of Animal Science, 52(1), 154-163. https://doi.org/10.2527/jas1981.521154x

Young, B. A. (1983). Ruminant cold stress: Effect on production. Journal of Animal Science, 57(6), 1601-1607. https://doi.org/10.2527/jas1983.5761601x 